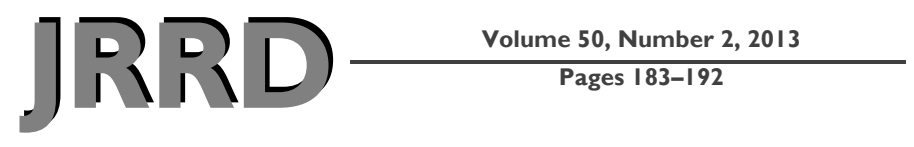

\title{
Effects of structured vocational services in ex-offender veterans with mental illness: 6-month follow-up
}

\author{
James P. LePage, PhD; ${ }^{*}$ Avery A. Lewis, MA; ${ }^{1}$ Edward L. Washington, BS; ${ }^{1}$ Brandi Davis, MS; ${ }^{2}$ Anne Glasgow $^{2}$ \\ ${ }^{l}$ Research and Development, Department of Veterans Affairs (VA) North Texas Health Care System, Dallas, TX; \\ ${ }^{2}$ Dallas VA Research Corporation, Dallas, $T X$
}

\begin{abstract}
With more than 200,000 veterans incarcerated, a significant need exists for the development of technologies that help veterans with felony histories return to employment. This study evaluated the effect of three methods of vocational assistance on competitive employment over a 6 mo follow-up period: (1) basic vocational services, (2) self-study using a vocational manual designed for formerly incarcerated veterans, and (3) a group led by vocational staff using the vocational manual. We evaluated 111 veterans for time to obtain and total time of competitive employment. The group format was expected to be superior to the self-study and the self-study superior to basic services. Findings indicated that the group format was associated with quicker employment and more total employment than the basic and self-study conditions. Limitations and directions for future refinement are discussed.
\end{abstract}

Clinical Trial Registration: ClinicalTrials.gov, NCT00648115, "Evaluating Vocational Materials for Incarcerated Veterans With Mental Illness or Substance Abuse";

http://www.clinicaltrials.gov/ct2/show/NCT00648115

Key words: employment, ex-offenders, homelessness, manualized treatment, mental illness, prison, self-help, substance dependence, veterans, vocational rehabilitation.

\section{INTRODUCTION}

A sizable veteran population is currently incarcerated. The most recently collected data from the Bureau of Justice from 2004 identified approximately 225,000 vet- erans incarcerated in prisons and jails across the country [1]. The majority, between 57 and 61 percent, are currently incarcerated for violent crimes. The other major domains accounting for current incarceration are property crimes (e.g., theft and burglary) at 13-17 percent, drug-related crimes (e.g., possession, distribution) at 1213 percent, and other crimes at 14 percent. Though no reliable national data exist on incarceration rates for Operation Iraqi Freedom/Operation Enduring Freedom veterans, data from the first gulf war found that approximately 8 percent of veterans who served during that period were arrested in the 4 yr following the conflict's end. Interestingly, deployment to a combat area was not a risk factor for arrest, though the presence of posttraumatic stress disorder (PTSD) was associated with incarceration [2].

An estimated 64,000 veterans are released back to the community each year [3]. Of these, a sizable portion

Abbreviations: $\mathrm{CWT}=$ Compensated Work Therapy; MIRECC $=$ Mental Illness Research, Education and Clinical Center; PTSD = posttraumatic stress disorder; SE = Supported Employment; VA = Department of Veterans Affairs; VHA = Veterans Health Administration; VISN = Veterans Integrated Service Network.

*Address all correspondence to James P. LePage, PhD; ACOS Research and Development, VA North Texas Health Care System, 4500 S Lancaster Rd, 151, Dallas, TX 75216; 214-857-0344. Email: james.lepage@va.gov http://dx.doi.org/10.1682/JRRD.2011.09.0163 
will be reincarceratated. Estimates place reincarceration rates of all prison releases between 45.3 [4] and 51.8 percent [5] over a $3 \mathrm{yr}$ period, translating to more than 33,000 of annually released veterans returning to incarceration.

Those who have been incarcerated will encounter a number of difficulties. One factor interrelated with incarceration is homelessness. Up to 40 percent reported some homelessness in the year before incarceration [6]. Rates of homelessness upon discharge range from 10 percent of Federal prison discharges [5] to 50 percent of State prisoners discharged to an urban setting [7].

Another factor is mental illness. A high percentage of incarcerated veterans experience mental health problems, with numbers ranging from 15 to 46 percent [8-9]. Veterans in State jails and Federal prisons, respectively, have 10 and 7 percent higher rates of mental health problems than nonveteran prisoners [1], and veterans with longterm incarceration histories have higher levels of psychiatric problems, drug use, and alcohol use. Depression is the primary mental health diagnosis, occurring with twice the frequency of all other diagnoses combined [8].

One of the largest challenges faced by incarcerated veterans and the more than 1.4 million Americans currently incarcerated [6] in State and Federal prisons is finding employment once released. After incarceration, in any given week, 40 percent of those with a felony history and 55 percent of black males with felony histories are unemployed [10]. The chances of getting hired are approximately 40 percent worse for those with a felony history than for those without [10-11] and unemployment rates have been found to be 15-25 percent higher $[10,12]$. Those with felony histories are frequently forced to take low-paying unskilled positions [13], resulting in lifetime earnings 10-30 percent lower than of those without a felony. LePage et al. found that even in a very supported residential environment with trained vocational staff, only 29.4 percent of homeless veterans with nonsubstance-related felonies found competitive employment; this was in contrast to 70.2 percent of those without felonies [14].

The inability to find stable employment contributes to additional difficulties, including homelessness. In a survey of incarcerated individuals with mental illness, 22 percent believed they would be homeless after release, with the number increasing to 43 percent for those with mental illness and substance abuse. Actual rates of homelessness for those released are as high as 50 percent for State prisoners released to urban areas [5]. The U.S. Con- ference of Mayors found that low-paying jobs and unemployment were two of the strongest influences on homelessness [15]. In fact, in dually diagnosed populations, employment, not chronicity of mental illness, was predictive of prolonged homelessness [16].

Relevant to the reentry population, employment is associated with lower rates of incarceration and reincarceration. Studies have shown that more than 30 percent of those arrested lacked full-time employment [5] and longer durations of employment were associated with reduced likelihood to commit both violent and nonviolent crimes [17]. Additionally, results from the Drug Treatment Alternative to Prison program found rearrest rates of 33 percent for those without employment, compared with 13 percent for those with employment [18].

The Department of Veterans Affairs (VA) has begun to address the needs of veterans involved in the criminal justice system through the development and encouragement of a number of different programs. Currently, each medical center has a Veterans' Justice Outreach Specialist, who is responsible for direct outreach, assessment, and case management for veterans in local courts and jails and liaison with local justice system partners. These specialists work with diversion courts for first-time offenders of nonviolent crimes. In Dallas, Texas, where the majority of veterans served by this program live, the Veteran's Diversion Court is still relatively young, having started in 2010, but these efforts to avoid prison are an important step in reducing the psychosocial impact of a history of incarceration. The Veterans Health Administration (VHA) also has dedicated Health Care for Re-entry Veterans Specialists to help veterans transitioning from prison to society connect to VA and local resources. Increasing these programs, which can prevent the impact of incarceration or ease the transition from incarceration, must be pursued to reduce the personal, economic, and societal impact of returning veterans.

Even with these services, a number of barriers to employment are encountered by released veterans attempting to obtain employment. Personal factors, such as low self-efficacy toward finding employment [19], external locus of control, and negative self-concept [2021], are associated with poor employment outcomes. External barriers, including stigma and statutory limitations, also contribute to poor employment rates [22]. Additionally, the natural consequences of incarceration, including job skill and technical ability erosion and poor social networks, work against the returning veteran. 
Finally, released veterans may not have the ability to describe to a potential employer their skills, abilities, work history, and prison experience in a way that allows them to be fairly considered for a job opening.

An additional and less obvious concern is employment saturation [6,23]. Employment saturation occurs when many released individuals live in the same neighborhoods and compete for the same low-paying jobs. This process serves to keep pay low for these individuals and make subsistence on legal revenue difficult.

The VHA provides a number of different veteran vocational opportunities that are available to veterans with felony histories. Programs such as Compensated Work Therapy (CWT) and Transitional Work Experience focus on work-hardening skills and employment preparation by providing veterans with temporary supervised employment opportunities either at the VA or in the community. Within CWT are Supported Employment (SE) programs, a vocational rehabilitation modality that uses an integrated approach to help people obtain and maintain community-based competitive employment in their chosen occupation [24-26]. SE is available for veterans with a variety of difficulties, including serious mental illness, polytraumatic injuries, and spinal cord injuries. Many Homeless Domiciliary Residential Rehabilitation and Treatment Programs provide job search skills and vocational services for their homeless residential patients. Though CWT and the Homeless Domiciliaries serve veterans with legal entanglements and histories, they do not specifically focus on the needs of the formerly incarcerated. If the full capacity of CWT $(10,800$ admitted to CWT in fiscal year 2009) and Domiciliaries (6,300 admitted in 2009) were used solely for released veterans, this would accommodate only 27 percent of the 64,000 veterans released annually.

To improve assistance to veterans with felony histories, the About Face vocational program and manual were developed. The About Face program incorporates information tailored for ex-offenders, such as interview skills, presentation of legal history, and description of job skills.

The About Face vocational program has been shown to be beneficial in helping veterans with felonies find employment [3]. In an evaluation of time to rapid employment, defined as obtaining employment within 3 mo, veterans were enrolled in one of three conditions: (1) basic (i.e., employment search without groups or the About Face manual), (2) self-study (i.e., search using the About Face manual in a self-study modality), and (3) full pro- gram (i.e., search following vocational staff-led classes using the About Face manual). Early findings from the About Face program showed that more participants in the full program quickly obtained employment $(23.8 \%)$ than in either the self-study (1.3\%) or basic $(0 \%)$ conditions. No differences were found between the self-study and basic conditions. However, this study took a narrow definition of employment success, specifically working at least $1 \mathrm{~d}$ of competitive employment over a 3 mo period.

The current study will expand on the initial study through a larger sample size and a broader definition of employment success, specifically, 6 mo employment rates, total time employed, and average monthly employment. Those in the full program are expected to have shorter time to employment and overall more time employed. The study will also seek to determine whether employment rates normalize over time.

\section{METHODS}

\section{Subjects}

We recruited 111 (108 male, 3 female) veterans with a history of at least one felony conviction and a mental illness and/or substance dependence/substance dependence in remission. Veterans were participating in the About Face vocational rehabilitation study, a VA Rehabilitation Research and Development-funded project. Participant characteristics were as follows: mean \pm standard deviation age $51.0 \pm 4.8 \mathrm{yr}, 94$ (91.0\%) from racial or ethnic minorities, and 43 (38.7\%) homeless. A total of 17 (15\%) met the criteria for PTSD, 45 (41\%) met criteria for a depressive disorder, 5 (4.5\%) met criteria for a psychotic disorder, and 101 (91\%) met criteria for a substance use disorder. At the time of enrollment, 43 (38.7\%) were homeless. Veterans living at the VA medical center at the time of enrollment, those with interfering psychosis, those with a diagnosis of dementia, and those seeking unemployability were excluded. During the 6 mo follow-up period, 13 (11.7\%) were rearrested. Four (3.6\%) required psychiatric hospitalization or inpatient mental health treatment. Based on self-report and patient medical records, 20 (18\%) used an illegal drug during the follow-up period.

\section{Setting and Description of Surrounding Area}

All were seen on the grounds of the Dallas VA Medical Center. The city of Dallas has seen a recent increase 
in unemployment, although the rates are generally lower than the national average for urban settings. Based on the Bureau of Labor Statistics (www.bls.gov/data), unemployment had increased from 4.4 percent in April 2008 to a high of 9.2 percent in January 2010. The rate stood at 8.8 percent in November 2010, the last month of the followup period.

Per the Texas Department of Public Safety, the city of Dallas had a crime rate higher than the overall state of Texas in 2010: 5,608 per 100,000 compared with the state rate of 4,236 . Murder (126\% higher), robbery (162\% higher), and theft (136\% higher) were the areas most at variance with the state means. Unfortunately, comparisons between cities for drug charges are not available.

Veterans arrested in the Dallas area for nonviolent first-time offenses related to substance use disorders are eligible to be seen by a Veteran's Diversion Court, which can mandate treatment as a condition to avoid incarceration. The VA North Texas Health Care System, which encompasses Dallas and the Dallas Medical Center, also has a Health Care for Re-entry Veterans Specialist to help veterans transitioning from prison to society connect to VA and local resources. An additional state of Texas service, though not limited to veterans, for those being released from State prison is Project RIO (Re-Integration of Offenders), which provides vocational services to those on parole or for up to $2 \mathrm{yr}$ after serving their full sentence.

\section{Materials}

The About Face Vocational Manual [3], , referred to from this point on as "the Manual," was developed through a Veterans Integrated Service Network (VISN) 16 Mental Illness Research, Education and Clinical Center (MIRECC) Education Grant. The Manual has a Flesch-Kincaid reading level of 6.8th grade. The Manual focuses on job-search activities such as answering difficult questions about incarceration, skill identification, and job-search strategies.

The Manual also incorporates sections on developing a basic but professional résumé. Examples are included, as well as a do-it-yourself section that allows veterans to "plug in" skills and examples. This section is tailored to

\footnotetext{
*Please see LePage et al. [3] for a detailed description of the manual
} development and content. be simple enough that someone with access to a word processor could create a résumé.

The Manual is available upon request in PDF format from the first author.

\section{Design Overview}

Three conditions were evaluated: (1) basic (i.e., selfdirected job search), (2) self-study (i.e., self-guided use of the Manual), and (3) full program (i.e., staff-led group focused on the Manual, followed by assisted job search). Vocational classes were offered once every 3 wk to assure adequate numbers of attendees were available, so condition assignment was based on the week of enrollment. This group assignment process and adjustments based on staff vacation/leave schedules contributed to disparate sample sizes in conditions; however, the sizes were statistically similar, $\chi^{2}(2,111)=4.1, p>0.10$.

For detailed methods, please see LePage et al. [3]. All participants had access to the Veterans Employment Resource Center, a dedicated area at the Dallas VA Medical Center that is staffed by vocational rehabilitation counselors and has internet access. All enrolled veterans completed a videotaped practice interview at enrollment and then a second videotaped practice interview $1 \mathrm{wk}$ later. In the full program, vocational staff reviewed and critiqued the interviews with the veteran. The basic and self-study conditions performed the interviews but received no feedback from staff; this procedure was implemented to control for potential effects of practicing interviews.

All veterans could be entered into a $\$ 100$ monthly raffle and receive bus passes for completion of follow-up paper work. All veterans in the study were asked to return at least once per month to update assessments and job-search status. Veterans could receive any non-studyrelated services.

\section{Outcomes}

Outcomes were focused on competitive employment. The definition of "competitive employment" was consistent with the Department of Labor's: paid position (1) not set aside for those with disabilities, (2) in a mainstream integrated setting, and (3) for at least minimum wage (\$7.25 per hour in Texas at the time of this study). Day labor and employment through a temporary agency without the possibility of the position becoming permanent were not considered employment. 
Four aspects of competitive employment were used for outcomes. The first aspect of competitive employment evaluated number of veterans who worked at least $1 \mathrm{~d}$ of competitive employment during the follow-up period. The second was time to obtain competitive employment, measured in months. The third outcome was the amount of time engaged in competitive employment, measured in months. The fourth outcome, which accounts for job loss, was the percentage of veterans competitively employed by month across the follow-up time.

\section{RESULTS}

As a result of the group assignment technique, 42 veterans were placed into the basic condition, 42 into the self-study condition, and 27 into the full program. Overall, there were no differences among groups in terms of racial/ethnic status, $\chi^{2}(6, n=111)=4.9, p>0.50$; drugrelated, $\chi^{2}(2, n=111)=0.05, p>0.50$, or violent felonies, $\chi^{2}(2, n=111)=2.9, p>0.20$; substance dependence, $\chi^{2}(2, n=111)=1.4, p>0.40$; comorbid substance- and mental health-related diagnoses, $\chi^{2}(2, n=111)=1.8, p>$ 0.30 ; marital status, $\chi^{2}(10, n=111)=11.8, p>0.30$; types of work being sought, $\chi^{2}(14, n=111)=11.5, p>$ 0.60 ; age, $F(2,108)=0.46, p>0.60$; number of felony convictions, $F(2,108)=0.26, p>0.70$; non-felony convictions, $F(2,111)=0.92, p>0.90$; time incarcerated in the past $10 \mathrm{yr}, F(2,111)=0.9, p>0.40$; suicide attempts, $F(2,111)=1.0, p>0.15$; and psychiatric hospitalizations, $F(2,111)=0.8, p>0.40$. The Table provides a breakdown by condition.

Vocational success was measured in several ways. The first was obtaining and working at least $1 \mathrm{~d}$ of competitive employment. Significant differences between conditions on the number of veterans finding competitive employment were found, $\chi^{2}(2, n=111)=9.0, p<0.05$. The full program (number hired $=11 ; 40.7 \%$ ) was superior to the basic (number hired $=7 ; 16.7 \%), \chi^{2}(1, n=69)=$ 4.9, $p<0.05$, and self-study conditions (number hired $=5$; $11.9 \%), \chi^{2}(1, n=69)=7.7, p<0.01$. No differences were found between the basic and self-study conditions, $\chi^{2}(1, n=84)=0.53, p>0.50$.

The time to employment was evaluated using Kaplan-Meier survival analyses (Figure 1). A significant difference was found between conditions, $\chi^{2}(2, n=111)=$ 11.0, $p<0.005$. Analyses of the specific comparisons between conditions found that the full program was sig-

Table.

Veterans' descriptive information by vocational rehabilitation condition.

\begin{tabular}{|c|c|c|c|}
\hline \multirow[b]{2}{*}{ Demographic } & \multicolumn{3}{|c|}{ Condition $^{*}$} \\
\hline & $\begin{array}{c}\text { Basic } \\
(n=42)\end{array}$ & $\begin{array}{l}\text { Self-Study } \\
(n=42)\end{array}$ & $\begin{array}{c}\text { Full Program } \\
(n=27)\end{array}$ \\
\hline$\overline{\text { Age, Mean } \pm \text { SD }}$ & $51.4 \pm 4.7$ & $50.0 \pm 4.5$ & $51.0 \pm 5.3$ \\
\hline Racial or Ethnic Minority, $n$ (\%) & 39 (92.9) & $38(90.5)$ & $24(88.9)$ \\
\hline Marital Status: Unmarried/Separated, $n$ (\%) & 39 (92.9) & 35 (83.3) & $26(96.3)$ \\
\hline Homeless, $n(\%)$ & $8(19.0)$ & $14(33.3)$ & $6(22.2)$ \\
\hline \multicolumn{4}{|l|}{ Crime } \\
\hline Violent, $n(\%)$ & $5(11.9)$ & $10(24.4)$ & $7(26.9)$ \\
\hline Drug-Related, $n$ (\%) & $23(54.8)$ & $22(52.4)$ & $14(53.8)$ \\
\hline No. of Felony Convictions, Mean \pm SD & $2.5 \pm 2.1$ & $2.8 \pm 1.8$ & $2.7 \pm 1.9$ \\
\hline No. of Arrests, Mean \pm SD & $7.6 \pm 9.5$ & $5.1 \pm 3.3$ & $5.5 \pm 2.9$ \\
\hline Months Incarcerated in Past 10 yr, Mean \pm SD & $26.4 \pm 30.6$ & $34.4 \pm 36.7$ & $24.7 \pm 31.0$ \\
\hline \multicolumn{4}{|l|}{ Mental Health } \\
\hline Substance Dependent, $n$ (\%) & 36 (85.7) & 35 (83.3) & $23(85.2)$ \\
\hline Comorbid Substance and Mental Health Diagnosis, $n$ (\%) & $21(50.0)$ & $15(35.7)$ & $13(48.1)$ \\
\hline No. of Psychiatric Hospitalizations, Mean \pm SD & $1.1 \pm 2.3$ & $0.7 \pm 1.5$ & $0.6 \pm 1.1$ \\
\hline No. of Suicide Attempts, Mean \pm SD & $0.3 \pm 0.3$ & $0.1 \pm 0.5$ & $0.3 \pm 0.7$ \\
\hline
\end{tabular}


JRRD, Volume 50, Number 2, 2013

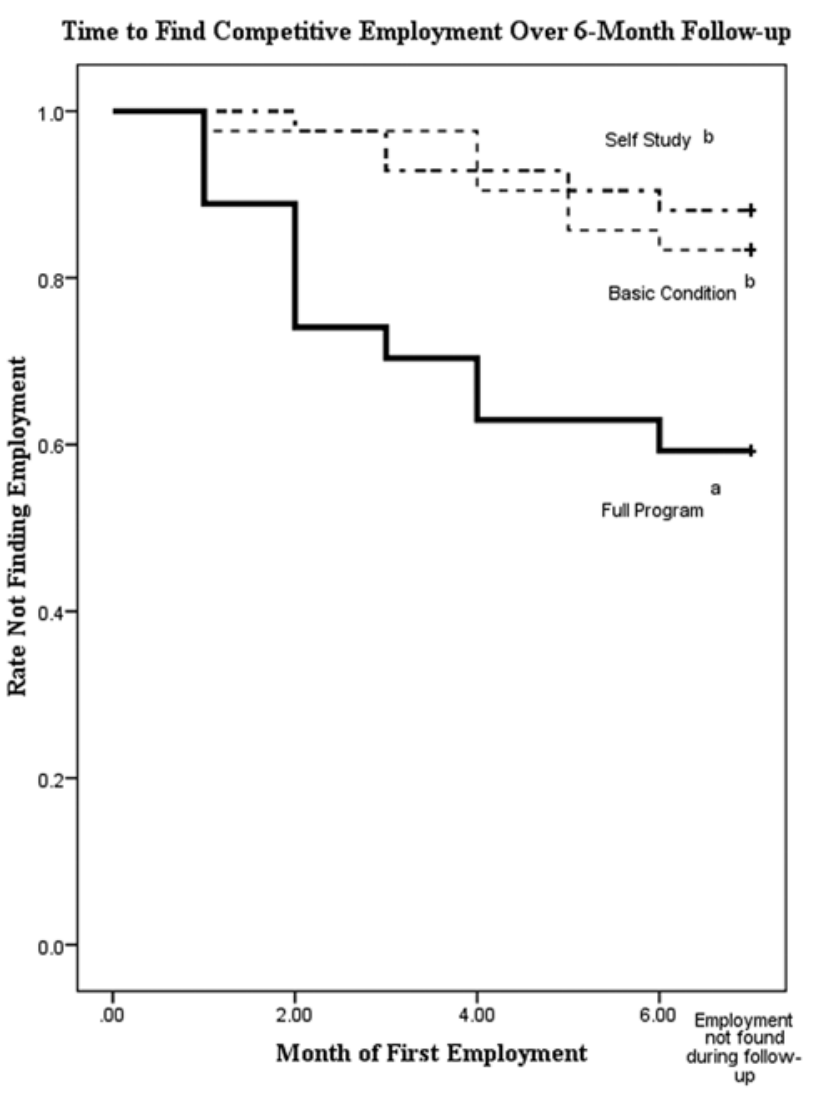

Figure 1.

Veterans' time to find competitive employment over 6 mo follow-up. Letters "a" and "b" indicate significant differences $(p<0.05)$.

nificantly different from both the basic, $\chi^{2}(1, n=69)=$ 5.9, $p<0.05$, and self-study conditions, $\chi^{2}(1, n=69)=$ 8.5, $p<0.005$. There was no significant difference between the basic and self-study conditions, $\chi^{2}(1, n=84)=$ $0.35, p>0.50$.

Amount of time employed in months was evaluated. This was computed on both the full samples and a subsample of only those who were hired in each condition. Overall, veterans in the full program (mean months employed $=1.37$ for full sample, 3.36 for those hired) worked more months than the basic (mean months employed $=0.35$ for full sample, 2.14 for those hired) and self-study conditions (mean months employed $=0.16$ for full sample, 1.4 for those hired). Because the distribution of months hired was heavily skewed because of the relatively high number with no employment, KruskalWallis tests were performed. The differences between conditions in the full sample, $\chi^{2}(2, n=111)=9.3, p<$
0.009 , and only those hired, $\chi^{2}(1, n=23)=6.1, p<0.05$, were both significant.

Finally, the number of veterans working each month across the 6 mo follow-up period was evaluated. This analysis is different than the time to employment in that it accounts for veterans who may have lost their jobs. Employment during a month was defined as working at least $1 \mathrm{~d}$ during the $30 \mathrm{~d}$ period. As can be seen by Figure 2, significant differences were found between conditions across the follow-up period. Most striking was the generally poor results for the self-study condition, for which no more than 5 percent of veterans were employed during any given month. Additionally, employment levels between the basic and full program conditions appeared to begin to equalize in month 5 .

An evaluation of demographic, clinical, and legal variables revealed no relationship with employment.

\section{DISCUSSION}

The results demonstrate that staff-led, formatted manualized vocational group programs can improve vocational outcomes for veterans with felonies. This study extends the narrower findings presented previously [3] by incorporating broader definitions of vocational success and a longer follow-up period.

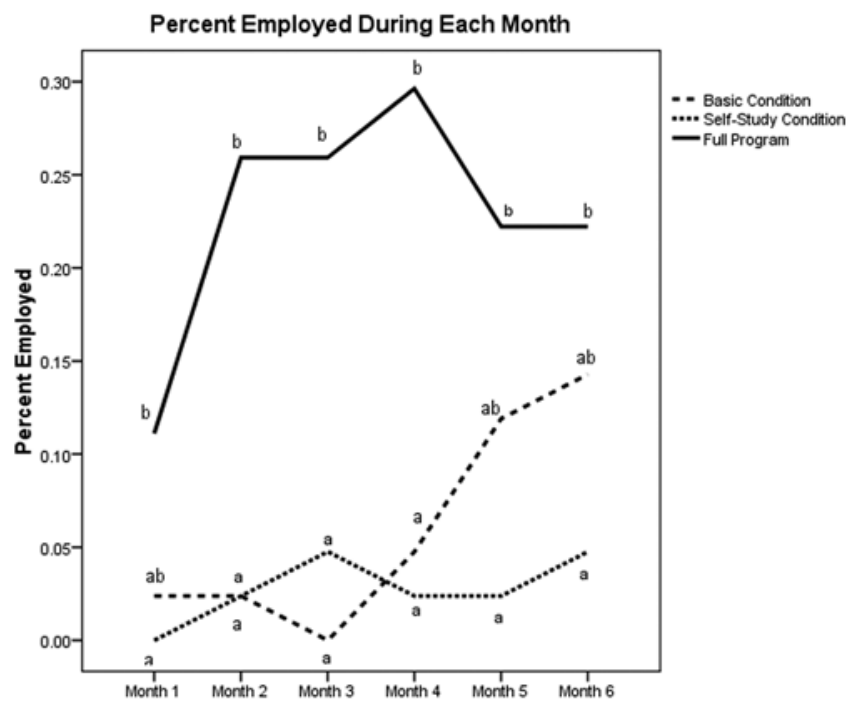

Figure 2.

Percentage of veterans employed during each month. Letters "a" and "b" indicate significant differences $(p<0.05)$. 
The findings continue to demonstrate the trend that self-study programs, at least as defined in this study, are no better than basic vocational services in helping veterans obtain employment. In fact, the introduction of selfstudy materials was trending toward inferiority with basic services. This trend is surprising and may indicate that providing education about a proper job search without modifying it for a veteran's specific needs or providing an opportunity to practice techniques in a controlled environment may actually interfere with success. What may be causing this interference is unclear. It may be hypothesized that veterans who have at least projected confidence in their previous poor responses now attempt to present unpracticed information in an unconfident manner. There is evidence from student populations that confidence in finding employment is an important predictor of success [27]. As such, the role of confidence, whether based on accurate or inaccurate self-assessment of ability, should be evaluated.

Anecdotal feedback from therapists and veterans suggested a number of areas from the group condition that were perceived as particularly helpful. Veterans felt that the ability to review and discuss how they would answer difficult questions was beneficial because it gave them confidence. One unusual caveat was that several veterans actually reported that they were less confident after the group; when probed, they reported that before the group the "didn't know what they didn't know" and were overconfident in their relatively poor job-search skills. Veterans also benefited from the ability to hear and see other veterans' responses to questions, particularly the interviews, and were able to incorporate the feedback the other veterans received into their presentation. Finally, the interaction with the vocational counselors who led the class was particularly helpful because it allowed the veterans to better tailor their responses to their unique circumstances.

Several limitations exist in the current study. Though the conditions appear similar in all relevant clinical, demographic, historical, housing, and legal variables, there may have been some aspects within the samples that were not measured and biased the results; these may have included severity of substance use, undisclosed information related to legal history (e.g., crimes against children), or goals to pursue disability. Though veterans who enrolled were expected to desire employment, this motivation could only be based on self-report. It was anecdotally noted that several of the veterans appeared motivated to remain in the study as long as bus passes were available, but did not use this resource to look for employment. Additionally, the use of assignment to condition by week of enrollment led to unequal sample sizes, though the numbers in the conditions were statistically similar. However, this group assignment technique could have introduced an unmeasured and systematic variable into the data. Though important to providing faster access to the services, this could have added error into the analyses.

The results have significant implications for the more than 200,000 incarcerated veterans. Vocational services targeting these veterans appears critical to rapid success. Because of ceiling effects, the follow-up period presented here cannot adequately determine whether the months employed or the trend toward similar employment rates is a stable finding. Extended follow-up periods will be required to address this issue.

The results point to several areas for future study. The effects of effort, confidence, and interviewing skills will be evaluated because these are likely to be affected by condition and partially account for the success in job search. Though the self-study condition has not been found successful, this type of intervention holds the most promise in terms of cost-effectiveness and may be critical to providing services to hard-to-reach veterans, such as homeless and rural populations. As such, some type of hybrid that incorporated Web-based components with examples and expert feedback could be developed. Also, developing measures of job search and job-maintaining self-efficacy for this population may be critical to the accurate assessment of success models. These projects are currently being pursued.

\section{CONCLUSIONS}

This study supports the use of the About Face manual in a group setting. Findings indicate that veterans using this program obtained employment sooner and spent more months employed over the 6 mo follow-up. Self-help activities were not supported and, considering previous findings, may be of limited use in their current form; finding ways to blend the self-study modality with staff feedback, such as through Web-based interactions, may hold promise.

The results support structured standardized groups focused on obtaining employment as a benefit to veterans 
with felony histories and should be incorporated into psychosocial treatment modalities that serve this population.

\section{ACKNOWLEDGMENTS}

\author{
Author Contributions: \\ Study design and concept: J. P. LePage. \\ Acquisition of data: A. A. Lewis, B. Davis, A. Glasgow. \\ Subject training: E. L. Washington. \\ Drafting of manuscript: J. P. LePage. \\ Material support: B. Davis. \\ Administrative support: A. Glasgow. \\ Database management: A. Glasgow. \\ Obtained funding: J. P. LePage.
}

Financial Disclosures: The authors have declared that no competing interests exist.

Funding/Support: This material was based on work supported the Rehabilitation Research and Development Service (Award D6192-R), VISN 16 MIRECC Clinical Education Grant Program, and VA North Texas Health Care Salary Support.

Institutional Review: This study was approved by the VA North Texas Health Care System's Institutional Review Board, and all participants provided informed consent.

Participant Follow-Up: The authors do not plan to inform participants of the publication of this study. However, participants have been encouraged to check the study Facebook page for updated publications.

\section{REFERENCES}

1. Noonan ME, Mumola CJ. Veterans in State and Federal prison, 2004. Report No.: NCJ 217199; Washington (DC): Bureau of Justice Statistics, U.S. Department of Justice; 2007.

2. Black DW, Carney CP, Peloso PM, Woolson RF, Letuchy E, Doebbeling BN. Incarceration and veterans of the first Gulf War. Mil Med. 2005;170(7):612-18. [PMID:16130644]

3. LePage JP, Washington EL, Lewis AA, Johnson KE, GarciaRea EA. Effects of structured vocational services on jobsearch success in ex-offender veterans with mental illness: 3month follow-up. J Rehabil Res Dev. 2011;48(3):277-86. [PMID:21480102] http://dx.doi.org/10.1682/JRRD.2010.03.0032

4. Pew Centers on the States. State of recidivism: The revolving door of America's prisons. Washington (DC): The Pew Charitable Trusts; 2011.

5. Langan PA, Levin DJ. Recidivism of prisoners released in 1994. Bureau of Justice Statistics Special Report. Report No.: NCJ 193427; Washington (DC): Bureau of Justice Statistics, U.S. Department of Justice; 2002.

6. Soloman AL, Johnson KD, Travis J, McBride EC. From prison to work: the employment dimensions of prisoner reentry. Washington (DC): Urban Institute, Justice Policy Center; 2004.

7. California Department of Corrections. Prevention parolee failure program: an evaluation. Sacramento (CA): California Department of Corrections; 1997.

8. La Vigne NG, Kachnowski V. Texas prisoners' reflections on returning home. Washington (DC): Urban Institute, Justice Policy Center; 2005.

9. Travis J, Soloman AL, Waul M. From prison to home: the dimensions and consequences of prisoner reentry. Washington (DC): Urban Institute, Justice Policy Center; 2001.

10. Freeman R. Crime and the employment of disadvantaged youth. In: Peterson G, Vroman W, editors. Urban labor markets and job opportunities.Washington (DC): The Urban Institute Press; 1992. p. 201-33.

11. Pager D. The mark of a criminal record. Am J Sociol. 2003;108:937-75. http://dx.doi.org/10.1086/374403

12. Western B, Kling JR, Weiman DF. The labor market consequences of incarceration. Crime Delinq. 2001;16:410-27. http://dx.doi.org/10.1177/0011128701047003007

13. Snyderman GS. Rehabilitating the ex-offender, ex-addict. Int J Addict. 1974;9(5):701-17. [PMID:4443146]

14. LePage J, Bluitt M, House-Hatfield T, McAdams H, Burdick M, Dudley D, Michaels S, Merrell C, Otto S, Lenger-Gvist J. Improving success in a veterans' homeless domiciliary vocational program: model development and evaluation. Rehabil Psychol. 2005;50:297-304.

http://dx.doi.org/10.1037/0090-5550.50.3.297

15. The U.S. Conference of Mayors. Hunger and homelessness survey. Washington (DC): The U.S. Conference of Mayors; 2003.

16. Leal D, Galanter M, Dermatis H, Westreich L. Correlates of protracted homelessness in a sample of dually diagnosed psychiatric inpatients. J Subst Abuse Treat. 1999;16(2): 143-47. [PMID:10023612] http://dx.doi.org/10.1016/S0740-5472(98)00021-X

17. Crutchfield RD, Pitchford SR. Work and crime: the effects of labor stratification. Soc Forces. 1997;76(1):93-118.

18. Sung $\mathrm{H}$. Rehabilitating felony drug offenders through job development: a look into a prosecutor-led diversion program. Prison J. 2001;81:271-86. http://dx.doi.org/10.1177/0032885501081002007

19. Michon HW, van Weeghel J, Kroon H, Schene AH. Personrelated predictors of employment outcomes after participation in psychiatric vocational rehabilitation programmesa systematic review. Soc Psychiatry Psychiatr Epidemiol. 2005;40(5):408-16. [PMID:15902412] http://dx.doi.org/10.1007/s00127-005-0910-5

20. Hoffman H, Kupper Z, Kunz B. Hopelessness and its impact on rehabilitation outcome in schizophrenia-an exploratory study. Schizophr Res. 2000;43(2-3):408-16. 
21. Hoffmann H, Kupper Z, Zbinden M, Hirsbrunner HP. Predicting vocational functioning and outcome in schizophrenia outpatients attending a vocational rehabilitation program. Soc Psychiatry Psychiatr Epidemiol. 2003;38(2): 76-82. [PMID:12563549] http://dx.doi.org/10.1007/s00127-003-0603-x

22. Holzer HJ, Raphael S, Stroll MA. Employment barriers facing ex-offenders. Washington (DC): Urban Institute, Justice Policy Center; 2003.

23. Visher C, La Vigne NG, Travis J. Returning home: understanding the challenges of prisoner reentry. Washington (DC): Urban Institute, Justice Policy Center; 2004.

24. Becker DR, Drake RE. Supported employment interventions are effective for people with severe mental illness. Evid Based Ment Health. 2006;9(1):22. [PMID:16436562] http://dx.doi.org/10.1136/ebmh.9.1.22

25. Bond GR, Becker DR, Drake RE, Rapp CA, Meisler N, Lehman AF, Bell MD, Blyler CR. Implementing supported employment as an evidence-based practice. Psychiatr Serv. 2001;52(3):313-22. [PMID:11239097] http://dx.doi.org/10.1176/appi.ps.52.3.313
26. Bond GR. Supported employment: evidence for an evidencebased practice. Psychiatr Rehabil J. 2004;27(4):345-59. [PMID:15222147] http://dx.doi.org/10.2975/27.2004.345.359

27. Saks AM. Multiple predictors and criteria of job search success. J Vocat Behav. 2006;68(3):400-415. http://dx.doi.org/10.1016/j.jvb.2005.10.001

Submitted for publication September 8, 2011. Accepted in revised form June 26, 2012.

This article and any supplemental material should be cited as:

LePage JP, Lewis AA, Washington EL, Davis B, Glasgow A. Effects of structured vocational services in ex-offender veterans with mental illness: 6-month follow-up. J Rehabil Res Dev. 2013;50(2):183-92. http://dx.doi.org/10.1682/JRRD.2011.09.0163

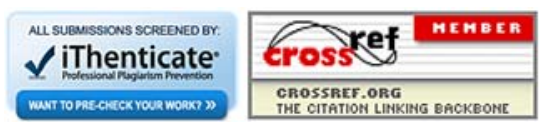


